\title{
A NEW PRECIPITATION-HARDENED AUSTENITIC STAINLESS STEEL INVESTIGATED BY ELECTRON MICROSCOPY
}

\author{
M. Dani ${ }^{1 *}$ Parikin $^{1}$, A. Dimyati ${ }^{1}$, A. K. Rivai ${ }^{1}$, R. Iskandar ${ }^{1}$ \\ ${ }^{1}$ Center for Science and Technology of Advanced Materials, BATAN, Kawasan Puspiptek, Serpong, \\ Tangerang, Banten 15314, Indonesia \\ ${ }^{1}$ Central Facility for Electron Microscopy (GFE), RWTH Aachen University, Ahornstrausse 55, \\ D-52074 Aachen, Germany
}

(Received: November 2017 / Revised: December 2017 / Accepted: January 2018)

\begin{abstract}
The $56 \mathrm{Fe} 16.6 \mathrm{Cr} 25 \mathrm{Ni} 0.9 \mathrm{Si} 0.5 \mathrm{Mn}$ austenitic superalloy has been produced in an induction furnace; it was made from granular ferro-scrap, ferrochrome, ferrosilicon, and ferromanganese materials. Originally, this alloy had been proposed for use in high mechanical loads and high temperature conditions (such as in nuclear and fossil fuel power plant facilities). Tensile strength tests showed that the alloy has an average yield strength of about $430.56 \mathrm{MPa}$, which is higher than Incoloy A-286 (a commercially available alloy). A combination of microscopy techniques by means of an optical microscope, X-ray diffraction [XRD], scanning electron microscopy [SEM], and transmission electron microscopy [TEM] techniques were applied in order to get detailed information about the fine structure of the alloy. XRD confirmed that the alloy matrix exhibits an FCC crystal structure with a lattice parameter of about $3.60 \AA$ and grain sizes ranging from 50 to $100 \mu \mathrm{m}$. The results of the TEM analysis revealed the new type of precipitations that formed at the grain boundaries. These needle-like precipitations, probably $\mathrm{Fe} / \mathrm{Cr}$-rich precipitations of the $(\mathrm{Fe}, \mathrm{Cr})_{\mathrm{x}} \mathrm{C}_{\mathrm{y}}$ type, acted as the source of intergranular corrosion (IGC). Small coherent plate-like and much smaller granular precipitations were found distributed homogenously along grain boundaries and inside the grains. Combining the tensile strength test and microstructure analysis suggested that these precipitations play significant roles in the hardness of the investigated sample.
\end{abstract}

Keywords: Austenitic super alloy steel; Precipitates; SEM; TEM; XRD

\section{INTRODUCTION}

To improve the performance of nuclear reactors (in terms of safety, proliferation resistance, economic performance, and minimization of waste), the six advanced generation IV reactor concepts (NEA, 2013) have been considered for use in advanced nuclear systems. The Indonesian National Nuclear Energy Agency (BATAN) is developing an experimental nuclear power plan with a capacity of $10 \mathrm{MW}$ thermic; this is meant to be an alternative for national energy consumption. The reactor would have a gas reactor operating at a high temperature (high temperature gas-cooled reactor, HTGR). One of the requirements for this type of reactor (especially for its structural materials, such as its vessel and heat exchanger) is that the material must exhibit high resistance to corrosion and creep; in addition, the material must be able to withstand mechanical loads at a high temperature and be resistant to neutron irradiation (Zinkle \& Snead, 2014). 
Graphite-based and carbon-based ceramic composites typically contain in-core structures. Those alloys have been identified (Taban et al., 2012) to have 2.25 percent $\mathrm{Cr}$ bainitic or 9 percent $\mathrm{Cr}$ martensitic steels for reactor pressure vessels, cross components, and intermediate heat exchangers. This will divert heat from the reactor's primary side to the hydrogen production plant. Such components place huge demands on their building materials. Therefore, durability in mechanical strength, creep, and corrosion is necessary for materials to have a prolonged life span of up to 20 years (NEA, 2013).

Using the framework of research programs for advanced materials, scientists of BATAN have successfully synthesized an austenitic superalloy using local content. The material belongs to the austenitic steel family; it is expected to have special characteristics, such as the ability to be a structural material for high temperature operations (Effendi, 2010; Effendi et al., 2012; Effendi \& Jahja, 2014).

The super alloy contains $56 \mathrm{Fe} 16.6 \mathrm{Cr} 25 \mathrm{Ni} 0.9 \mathrm{Si} 0.5 \mathrm{Mn}$ austenitic. It has been proposed that this austenitic steel will be useful as a structural component in multipurpose facilities (i.e., reactor structural materials). Therefore, it could be resistance (Darwinto \& Jahja, 2010; Effendi et al., 2014; Wahyono et al., 2015) to mechanical loads, high temperatures, corrosion, and irradiation (especially to neutron scattering from reactors).

To produce a low-carbon austenitic alloy (Kanthavela et al., 2014), non-standard chemical compositions can be prepared in a laboratory-scale fabrication process using a casting method.

Since to many elements introduced in the super alloy and few comprehensive characterization have been done, this study try to investigate some intermetallic compounds and second phases formed in the alloy using scanning electron microscope, transmission electron microscope, focused ion beam technique and x-ray diffractometer. In this report, the results of microstructure investigations of this alloy are presented. The main aim of this research is to understand the alloy's properties of mechanical and corrosion resistance, which are important if it is to be applied as a reactor structure material.

\section{EXPERIMENTAL SETUP}

The alloys were made from granular scraps of chrome steel, steel scraps of plain carbon, FeSi75, and low-carbon FeCr65 (with the addition of pure nickel, FeMn, slag remover, and pure aluminum). These raw materials were melted in an induction furnace. The aluminum was used for degassing. Then, these casting processes were followed by commercial production procedures.

Small amounts of the plain $\mathrm{FeC}$ and $\mathrm{FeCr}$ scraps were inserted into the first induction furnace while they were still cold. The mixture was then heated by increasing the current to $180 \mathrm{KW}$ for about one hour until the mixture had liquefied entirely. The same material mixture was added little by little up to its final mass. FeMn, pure Ni, FeCr 65, and FeSi75 were poured into the melt at a temperature of $1480^{\circ} \mathrm{C}$. The composition was checked and controlled at a temperature of $1520^{\circ} \mathrm{C}$. The desired composition was achieved by the successive addition of materials. Tapping fluid was accompanied by the addition of aluminum in the ladle, which was used for degassing. Tapping was performed at a temperature of $1600^{\circ} \mathrm{C}$. No further treatments (such as homogenizing) were performed on these alloys. The finished alloy contained $25.04 \%$ wt. Ni and $16.55 \%$ wt. Cr; this gave the material the characteristics of high strength and high corrosion resistance. However, the alloy had low Mn, Al, and Ti concentrations, which were 0.504, 0.003, and $0.004 \%$ wt., respectively.

The composition of the synthesized alloy was measured by optical emission spectroscopy (OES). The results (shown in Table 1) revealed that the alloys contain $25.04 \%$ wt. Ni and $16.55 \%$ wt. Cr. 
It can be expected that the alloy, due to its composition, will have the characteristics of high strength and high corrosion resistance. However, the alloy has quite low $\mathrm{Mn}, \mathrm{Al}$, and $\mathrm{Ti}$ concentrations, which are $0.504,0.003$, and $0.004 \%$ wt., respectively. For comparison, Incoloy A-286 (a commercial austenitic superalloy) is also presented in Table 1.

Table 1 The chemical composition (in weight percentage) of the as-cast alloy and Incoloy A-286 (CarTech ${ }^{\circledR}$ A-286 Alloy, 2018), which were analyzed by OES

\begin{tabular}{ccccccccccc}
\hline Element & $\mathrm{Fe}$ & $\mathrm{Ni}$ & $\mathrm{Cr}$ & $\mathrm{Si}$ & $\mathrm{C}$ & $\mathrm{Mn}$ & $\mathrm{Al}$ & $\mathrm{Ti}$ & $\mathrm{P}$ & $\mathrm{V}$ \\
\hline As-Cast Alloy & Bal. & 25.04 & 16.55 & 0.89 & 0.293 & 0.504 & 0.003 & 0.004 & 0.013 & - \\
Incoloy A-286 & Bal. & 24.93 & 14.90 & 0.63 & 0.068 & 1.320 & 0.190 & 2.150 & - & 0.210 \\
\hline
\end{tabular}

In this work, the as-cast alloy was investigated without any further treatment (such as homogenizing). The alloy was subjected to tensile strength and Charpy tests. Every test was repeated three times to ensure representative results. The tensile tests followed the ASTM E8M04.

After the tests, a small piece of the alloy (with dimensions of $10 \times 10 \times 5 \mathrm{~mm}$ ) was cut and used for microstructure analyses. For optical and SEM observations, specimens were prepared by using metallography techniques. The specimens were cut from the bulk material along its long axis, and they were grinded with sand paper until they were grade 2000 mesh. Subsequently, they were polished with an alumina suspension of $1 \mu \mathrm{m}$. The specimens were etched using Kalling's reagent $\left(\mathrm{HCl}\right.$ and $\left.\mathrm{CuCl}_{2}\right)$ solution. The surface morphology of the bulk specimen was analyzed using a thermionic scanning electron microscope Quanta 650 from FEI, which was equipped with an EDX detector from Oxford.

Detailed microstructure analyses were performed by using transmission electron microscopy (TEM) techniques. For this purpose, a TEM lamella was prepared by means of focused ion beam (FIB) techniques on an FIB workstation from Hitachi FB2200; it was investigated by TEM to reveal the fine structure and crystal lattice parameter of the precipitate. Details of the FIB process have been given elsewhere (Reuteler, 2016; Zhang et al., 2017). The TEM analysis was employed by using an $\mathrm{H} 9500$ Hitachi microscope that was operated at $300 \mathrm{kV}$; it was also equipped with an EDX detector from EDAX.

\section{RESULTS AND DISCUSSION}

\subsection{Mechanical Properties}

The tensile test revealed that the alloy exhibited strengths ranging from 388.58 to $499.68 \mathrm{MPa}$, which is lower than that of Incoloy A-286, which has been commercially available since the 60s (Figure 1).

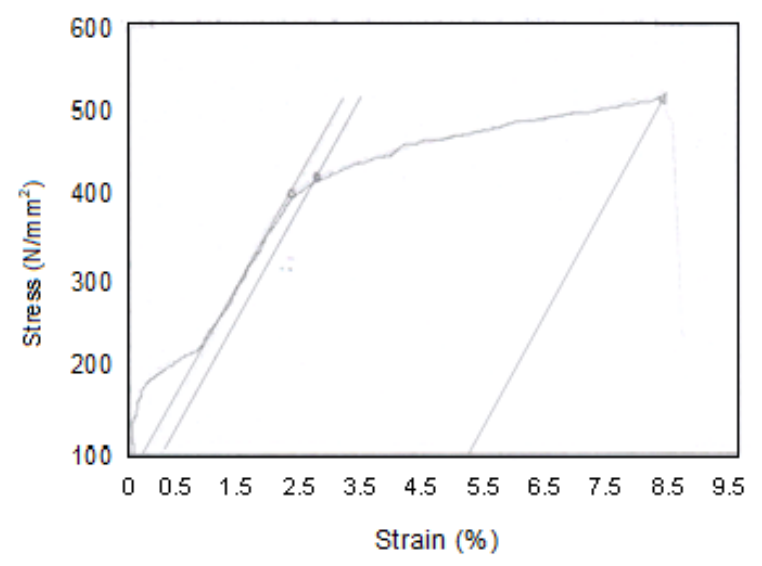

Figure 1 Tensile test results on an as-cast alloy in a tensile test curve 
In addition, its yield strength of $430.56 \mathrm{MPa}$ is slightly lower than that of A-286. However, its $0.2 \%$ yield strength was $266 \mathrm{MPa}$, which is quite high.

The synthesized steel showed an ultimate stress of about $518 \mathrm{MPa}$ at its break point. It did not experience elongation before it broke because it is quite brittle. This was shown by the hardness measurements, which were carried out with the Vickers method; the mean hardness value was about $150 \mathrm{HVN}$, which was taken at a load of $30 \mathrm{kgf}$. The hardness to yield strength ratio was about 0.38, which is consistent with previous works (Al-Badairy et al., 2003).

The maximum load of the Charpy test at room temperature was measured to be 1.32 joules. After the Charpy test, the specimen indicated a brittle fracture (as can be seen in the SEM image in

Figure 2). The cut off surface seemed to contain intergranular cracks.

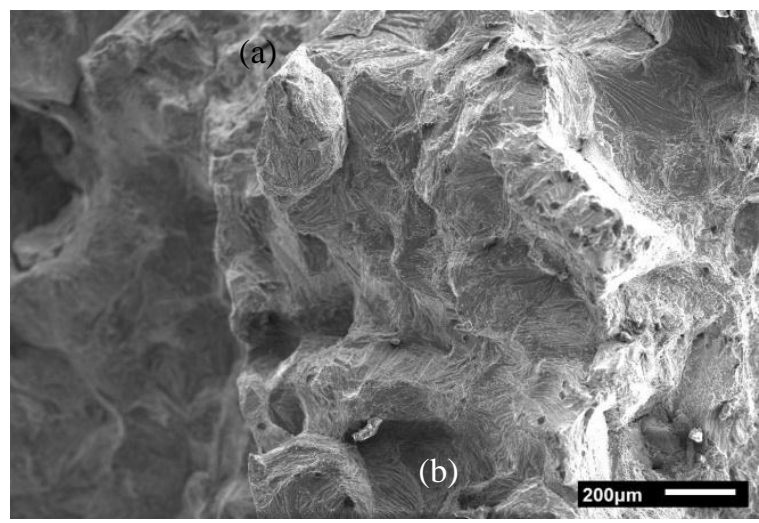

Figure 2 Impact test results on an as-cast alloy in a fracture after the Charpy Test, which was recorded at the cross section by using SEM

\subsection{Microstructures}

The results of the microscope optic observation of the polished specimen are shown in Figure 3. No crystal twins can be identified, which indicates austenitic structures.

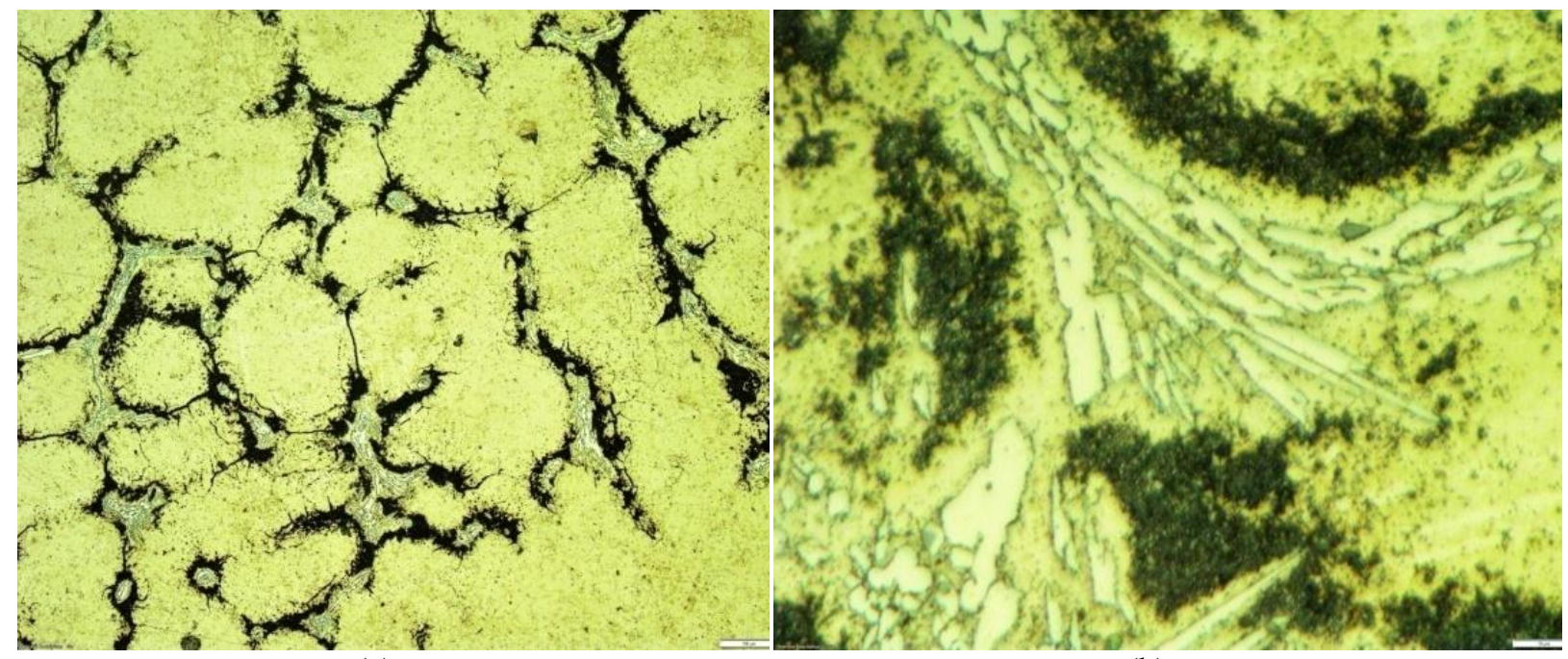

(a)

(b)

Figure 3 Metallographic structure of the alloy observed in an optical microscope, showing: (a) the large grain boundary; and (b) the small granular precipitations around and inside the grains

Figure 4 shows a detailed view of the grain boundary, which was taken by the SEM. As can be seen in the optical microscope images, precipitates with typical elongated forms were found along the grain boundaries. Many small precipitates covered the outer grains that contained $\mathrm{Cr}_{\mathrm{x}} \mathrm{C}_{\mathrm{y}}$ 
compounds. Based on Figure 5, the EDX semi-quantitatively counts this area, which contains 21.5\%wt. $\mathrm{Cr}$ and $9.5 \%$ wt. $\mathrm{C}$, as shown in the $5^{\text {th }}$ spectrum column of Table 2. Meanwhile, oxygen was trapped in the pores and was captured by carbon atoms (as shown in the $3^{\text {rd }}$ spectrum column of Table 2).

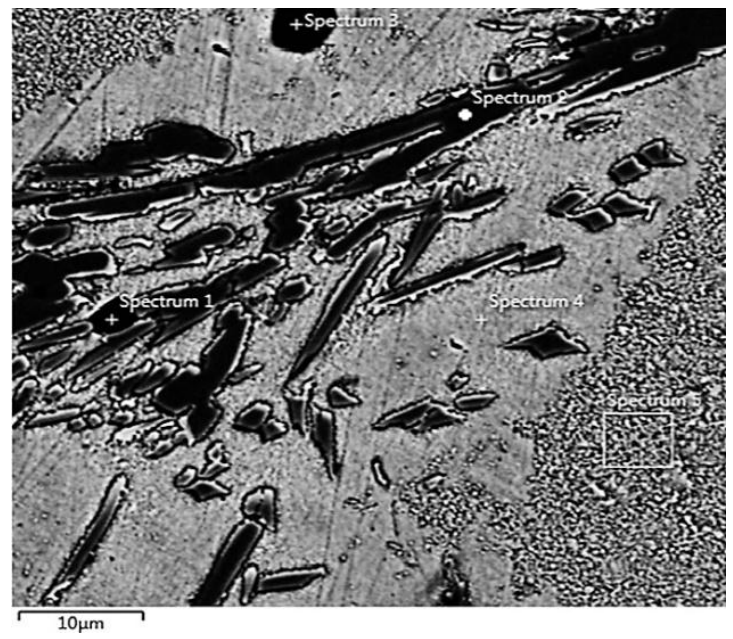

Figure 4 SEM BSE image and EDS map of precipitates formed at the grain boundary

The EDX map in Figure 5 reveals the precipitations that contain Fe/Cr-rich phases. The elements are clearly detected with different color displays (i.e., green for Fe elements, red for Cr elements, blue for Ni elements, and purple for $\mathrm{C}$ elements). Furthermore, the EDX point ID analysis was taken from several areas (indicated by numbers in the image), proving that each phase occurred.
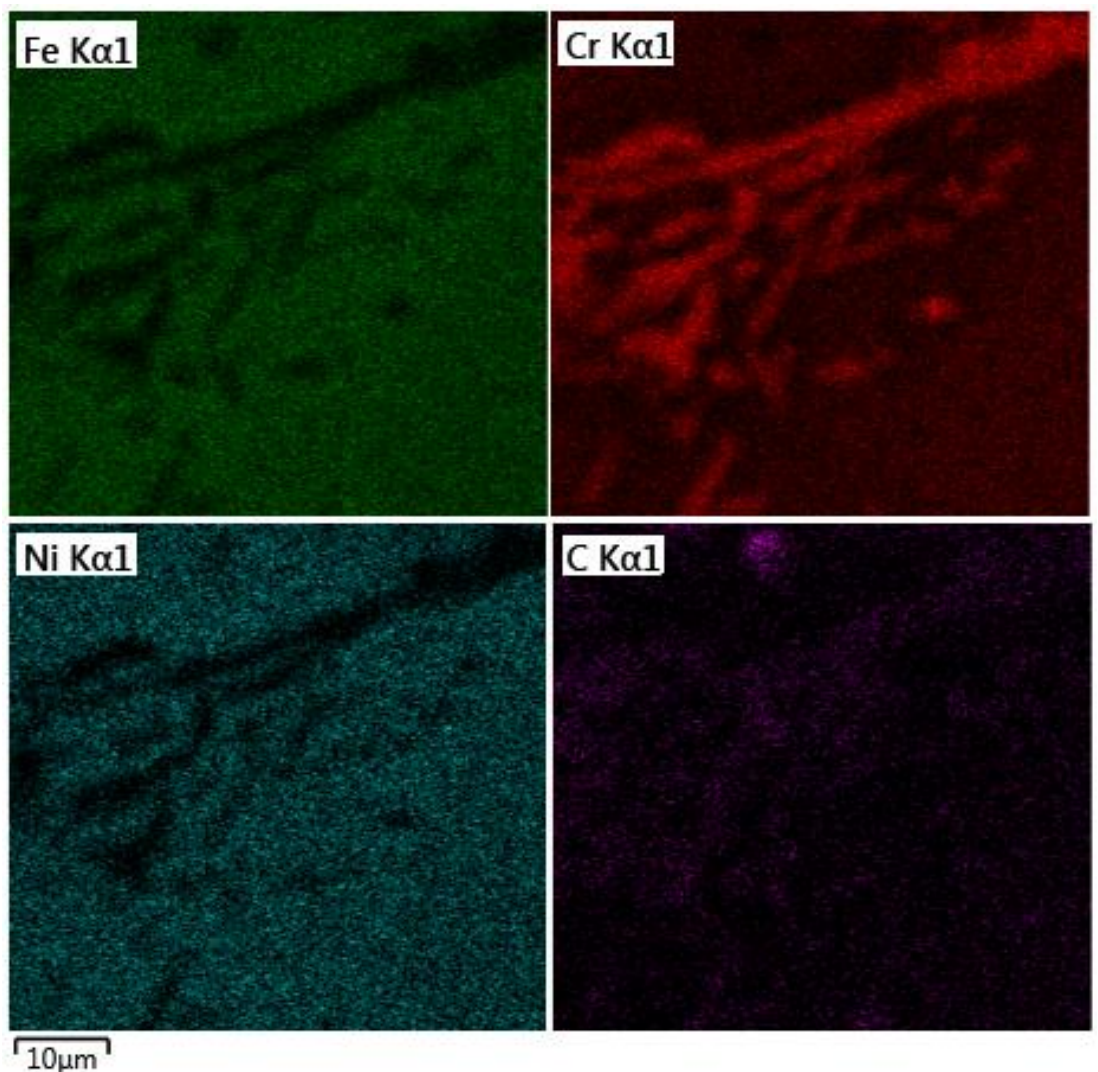

Figure 5 EDX mapping of $\mathrm{Fe}, \mathrm{Cr}, \mathrm{Ni}$, and $\mathrm{C}$ elements at the grain boundary

The results, as presented in Table 2 , show that the main precipitates are $(\mathrm{Fe}, \mathrm{Cr})_{\mathrm{x}} \mathrm{C}_{\mathrm{y}}$, including single MnS, which could be the impurity during melting. 
Table 2 Elemental composition of $56 \mathrm{Fe} 15 \mathrm{Cr} 25 \mathrm{Ni} 0.9 \mathrm{Si} 0.5 \mathrm{Mn}$ austenitic superalloy steel (SEM-EDX)

\begin{tabular}{lcrccc}
\hline Element & $\begin{array}{c}\text { \%wt. } \\
\text { Spectrum-1 }\end{array}$ & $\begin{array}{c}\text { \%wt. } \\
\text { Spectrum-2 }\end{array}$ & $\begin{array}{c}\text { \%wt. } \\
\text { Spectrum-3 }\end{array}$ & $\begin{array}{c}\text { \%wt. } \\
\text { Spectrum-4 }\end{array}$ & $\begin{array}{c}\% \text { wt. } \\
\text { Spectrum-5 }\end{array}$ \\
\hline $\mathrm{Fe}$ & 4.9 & 14.9 & 25.7 & 51.3 & 46.4 \\
$\mathrm{Ni}$ & 0.9 & 1.0 & 13.7 & 23.8 & 21.7 \\
$\mathrm{Cr}$ & 28.7 & 69.1 & 10.1 & 16.5 & 21.5 \\
$\mathrm{C}$ & 10.8 & 14.3 & 35.0 & 7.1 & 9.5 \\
$\mathrm{Si}$ & - & - & 0.6 & 1.3 & 1.0 \\
$\mathrm{Mn}$ & 17.5 & - & - & - & - \\
$\mathrm{S}$ & 26.4 & - & - & - & - \\
$\mathrm{O}$ & - & - & 10.9 & - & - \\
\hline
\end{tabular}

TEM bright-field image analysis showed that the precipitates formed close to the surface area (Figure 6). A few dislocations existed inside the grains. Two types of precipitates can be observed; the large ones have a plate-like morphology, and the small ones are granularly shaped (being a few nanometers in size). The large precipitates are orientation dependent. Parallel straight lines are also present, which are occupied by the small particles.
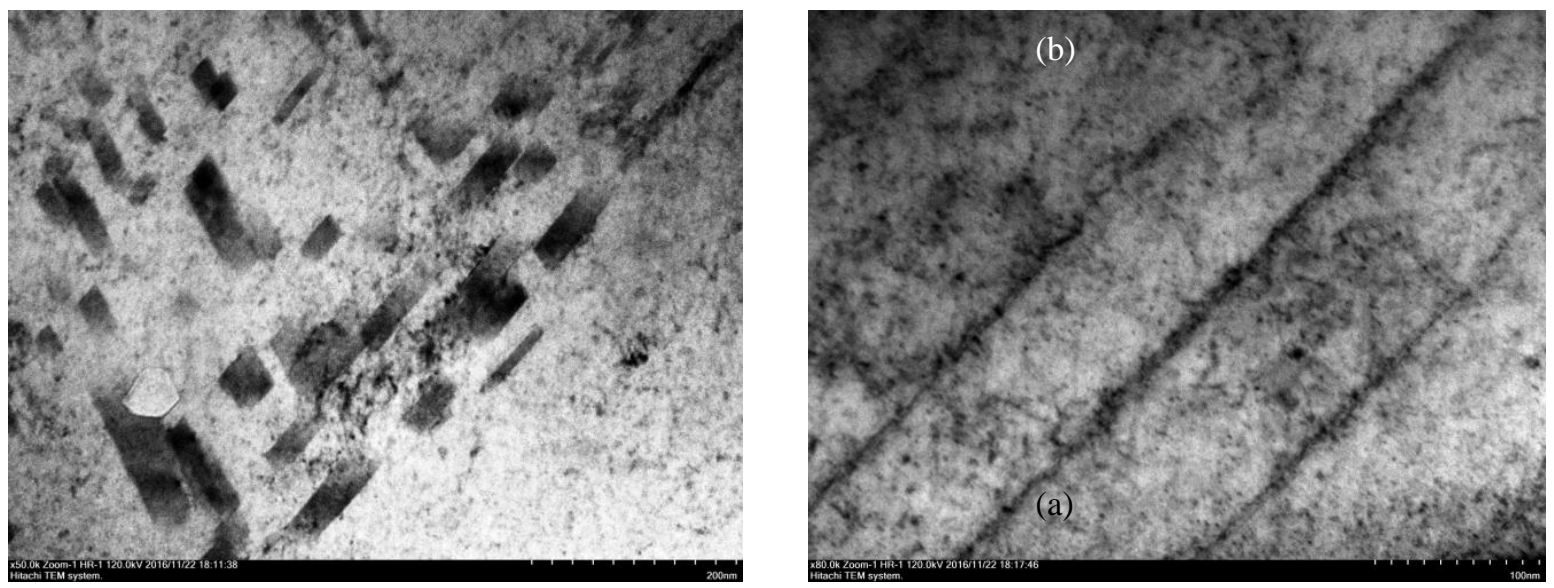

Figure 6 TEM bright-field image of precipitates formed: (a) inside the grain $(200 \mathrm{~nm}, 50 \times)$; and (b) at straight line grain boundaries $(100 \mathrm{~nm}, 80 \times)$

\subsection{Crystal Structure}

The XRD revealed that the $56 \mathrm{Fe} 15 \mathrm{Cr} 25 \mathrm{Ni} 0.9 \mathrm{Si} 0.5 \mathrm{Mn}$ austenitic alloy has a single FCC structure with a lattice parameter of about $3.60 \AA$ (see Figure 7). Refinements, which were carried out by using the Rietveld method (Dani et al., 2015), indicated that the alloy has the reciprocal latticei.e., (111), (200), (220), (311) and (222) - which extends in the interval angle of $2 \theta$ between $30^{\circ}$ and $120^{\circ}$. The goodness-of-fit parameters look very reliable due to their values of $R_{w p}=3.21$ and $S$-factor $=1.21$, which indicate that this alloy perfectly fits in the face-centered cubic space group. 


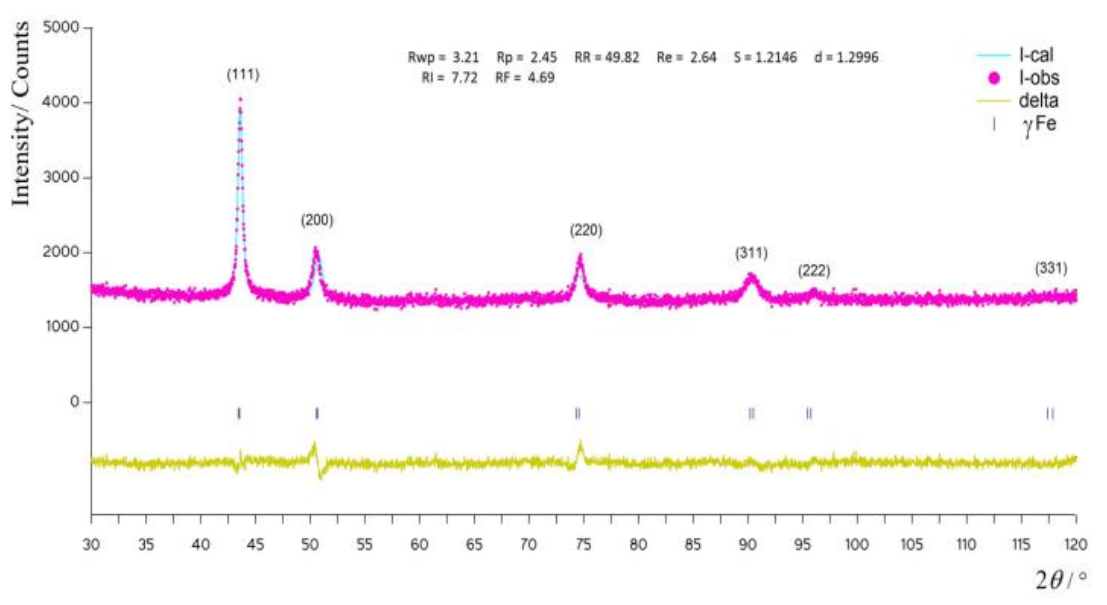

Figure $7 \mathrm{X}$-ray diffraction pattern of $56 \mathrm{Fe} 15 \mathrm{Cr} 25 \mathrm{Ni} 0.9 \mathrm{Si0} .5 \mathrm{Mn}$ austenitic steel

The precipitates' presence was confirmed by the TEM and selected area electron diffraction (SAED), as shown in Figure 8. Both types of precipitations are observable in the SAED as spot and ring diffraction patterns (big faint circles).

Based on the SAED analysis, the matrix was indicated to be in the (111) orientation. The precipitates' orientation relationship to the matrix was $\langle 111\rangle \mid /\langle 120\rangle$. The solid ring confirmed that the small particles have a crystalline structure. The measured diffraction spots of the first precipitate gave the lattice spacing $a=3.60 \AA$, which was identified as FCC and was in full agreement with the result of the XRD. In accordance with the relationship to the matrix, the large precipitates stand in a good orientation relationship with the matrix. Identification of electron diffraction resulted in the lattice information of an orthorhombic structure with $a=11.47 \AA, b=$ $5.54 \AA$, and $c=2.83 \AA$. This was identified to be the same phase as large precipitates.

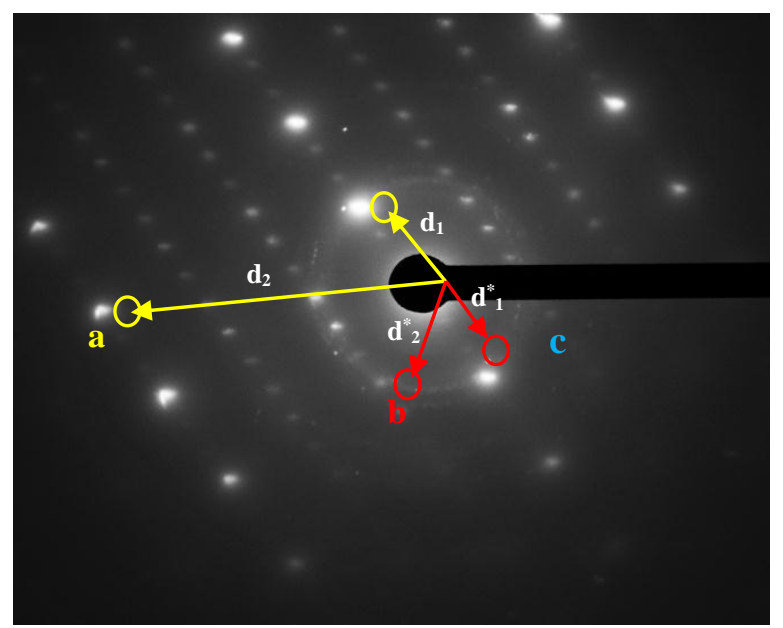

Figure 8 Diffraction pattern of the (a) matrix (yellow circles), (b) large precipitates present as diffraction spots (red circles), and (c) small precipitates in the form of a weak diffraction ring (big faint circle)

The mechanisms of hardening and corrosion (as well as oxidation resistance) in high alloyed steel are well known, and they have been reported in many publications (Sumijanto et al., 2015; Parikin et al., 2017; Besnard et al., 2017; Geers et al., 2017). In this work, it was assumed that the hardening mechanism of the alloy was associated with the presence of precipitation. However, it is the small precipitations that contributed most to the hardness. The role of the larger grain boundary precipitation in the alloy's strength was unclear. The lower yield strength may have originated from the absence of $\mathrm{Ti}$, which mainly forms the Gamma prime precipitate; this is 
common in austenitic superalloys, as stated in the literature (Chen et al., 2015; Ramírez et al., 2016; Belan et al., 2017), due to the higher C content. Furthermore, the large precipitation at the grain Chyrkin et al., 2017; boundary seemed to create intergranular fractures during the fatigue test; this contributed to decreasing the yield strength. In contrast to A-286, this alloy did not form a second hardening phase $\mathrm{Ni}(\mathrm{Ti}, \mathrm{Al})_{3}$ but could be a carbide of type $\mathrm{Cr}-\mathrm{C}$. Thus, the strengthening mechanism may be different from that in Incoloy A-286.

The reason for the absence of a twin (which is usually present in austenitic alloys) is unclear. It may have been caused by the relatively long cooling time, or it could have been due to unfinished etching. It was not easy to etch this microstructure because of the alloy's high resistance to acid attacks.

Coherent and incoherent precipitations occur inside the grains. There are large plate-like precipitations (with sizes ranging from 25 to $100 \mathrm{~nm}$ ) and smaller particles of the carbide type. These precipitations are coherent to the matrix, which could contribute to the high hardness. The latter may elucidate the exceptionally high strength of this alloy. As can be seen in Figure 5, a large number of dislocations were pinned via the Orowan mechanism (Lehtinen et al., 2016; Kalandyk et al., 2017), forming the main movement blocking; this represents the increase in strength. The precipitate size distribution seems to not depend on the lattice mismatch, which confirmed the finding of Tovar et al. (2017). However, the presence of a large plate-like precipitation in the grain boundaries may make this alloy more prone to intergranular stress corrosion cracking (IGSCC). This requires further investigation.

\section{CONCLUSION}

A 56Fe15Cr25Ni0.9Si0.5Mn austenitic superalloy steel was successfully synthesized from ferroscrap, ferrochrome, ferrosilicon, and ferromanganese by using an induction furnace with a yield strength higher than that of the commercially available A-286 alloy (i.e., $430.56 \mathrm{MPa}$ ).

The XRD confirmed a lattice parameter of about $3.60 \AA$ with typical lattice planes of (111), (200), (220), (311), and (222), which extended in the interval angle of $2 \theta$ between $30^{\circ}$ and $120^{\circ}$.

The microstructure of the specimen exhibited $(\mathrm{Fe}, \mathrm{Ni}, \mathrm{Cr})_{\mathrm{x}} \mathrm{C}_{\mathrm{y}}$ precipitation, which was distributed along the grain boundary; this can be observed in typical elongated grains and sub-grains. The results of the SEM investigation (BSE technique) of the microstructure showed that there was ferro-chromium carbide and a small amount of impurity (such as $\mathrm{MnS}$ ).

\section{ACKNOWLEDGEMENT}

The authors would like to express their gratitude to Mr. Gunawan, the head of the Center for Science and Technology of Advanced Material at the National Nuclear Energy Agency, for his support. The authors would also like to express their gratitude to Dr. Damar Rastri Adhika from the Research Center for Nanosciences and Nanotechnology ITB - Bandung Indonesia, for the opportunity to do the transmission electron microscopy analysis that was presented in this work. In addition, the authors would like to thank Mr. Bambang Sugeng for the XRD analysis.

\section{REFERENCES}

Al-Badairy, H., Naumenko, D., Coze, J.L., Tatlock, G.J., Quadakkers, W.J., 2003. Significance of Minor Alloying Additions and Impurities on Alumina Scale Growth and Adherence in FeCrAl Alloys. Materials at High Temperatures, Volume 20, pp. 405-412

Belan, J., Vaško, A., Tillová, E., 2017. Microstructural Analysis of DV-2 Ni-base Superalloy Turbine Blade after High Temperature Damage. Procedia Engineering, Volume 177, pp. $482-487$ 
Besnard, M.R.A., Popa, I., Heintz, O., Chassagnon, R., Vilasi, M., Herbst, F., Girardon, P., Chevalier, S., 2017. Effect of Surface Finishing on the Oxidation Behaviour of a Ferritic Stainless Steel. Applied Surface Science, Volume 412, pp. 196-206

CarTech $^{\circledR}$ A-286 Alloy., 2018. Product DataSheet, Carpenter Technology Corporation Wyomissing, PA, USA. https://www.cartech.com/en/product-solutions/cartech-a286-alloy/

Chen, C., Wang, Z., Kato, T., Shibata, N., Taniguchi, T., Ikuhara, Y., 2015. Misfit Accommodation Mechanism at the Heterointerface between Diamond and Cubic Boron Nitride. Nature Communications, Volume 6, pp. 1-6

Chyrkin, A., Pillai, R., Galiullin, T., Wessel, E., Grüner, D., Quadakkers, W.J., 2017. External $\alpha-$ $\mathrm{Al}_{2} \mathrm{O}_{3}$ Scale on Ni-base Alloy 602 CA. - Part I: Formation and Long-term Stability. Corrosion Science, Volume 124, pp. 138-149

Dani, M., Untoro, P., Putra, T.Y.S.P., Parikin, Mayer, J., Dimyati, A., 2015. Transmission Electron Microscopy Characterization of High-temperature Oxidation of Fe-20Cr-5Al Alloy Prepared by Focused Ion Beam Technique. Makara Journal of Technology, Volume 19(2), pp. 85-89

Darwinto, T., Jahja, A.K., 2010. Analysis of Microstructure and Crystal Structure on the Ferritic F1. Indonesian Journal of Material Science, Volume 11(2), pp. 202-206

Effendi, N., Jahja, A.K., Bandriana, Adi, W.A., 2012. Some Data of Second Sequence Non Standard Austentic Ingot A2-Type. Urania, Scientific Journal of Nuclear Fuel Cycle, Volume 18(1), pp. 48-58

Effendi, N., 2010. Austenitic Stainless Steel Production by Foundry. Urania, Jurnal Ilmiah Daur Bahan Bakar Nuklir, Volume 16(2), pp. 69-77

Effendi, N., Darwinto, T., Ismoyo, A.H., Parikin, 2014. 24-Chromium Ferritic Steel Magnetic Properties. Indonesian Journal of Material Science, Volume 15(4), pp. 187-191

Effendi, N., Jahja, A.K., 2014. Structural Characterization and Its Physical Properties of NonStandard A1 Austenite Steel. International Journal of Materials and Mechanical Engineering, Volume 3(2), pp. 38-44

Geers, C., Babic, V., Mortazavi, N., Halvarsson, M., Jo“nsson, B., Johansson, L.G., Panas, I., Svensson, J.E., 2017. Properties of Alumina/Chromia Scales in $\mathrm{N}_{2}$-Containing Low Oxygen Activity Environment Investigated by Experiment and Theory. Oxidation Metals, Volume 87, pp. 321-332

Kalandyk, B., Zapała, R., Starowicz, M., 2017. The Effect of Si and Mn on Microstructure and Selected Properties of Cr-Ni Stainless Steels. Archives of Foundry Engineering, Volume 17(1), pp. 192-196

Kanthavela, K., Arunkumar, K., Vivek, S., 2014. Investigation of Chill Performance in Steel Casting Process using Response Surface Methodology. Procedia Engineering, Volume 97, pp. 329-337

Lehtinen, A., Granberg, F., Laurson, A., Nordlund, K., Alava, M.J., 2016. Multi-scale Modeling of Dislocation-precipitate Interactions in Fe: From Molecular Dynamics to Discrete Dislocations. Journal of Materials Science (cond-mat.mtrl-sci), Physical Review E, Volume 93, pp. 1-10

NEA, 2013. Status Report on Structural Materials for Advanced Nuclear Systems, Nuclear Energy Agency Organization for Economic Co-operation and Development. OECD, NEA, No. 6409

Parikin, Ismoyo, A.H., Dimyati, A., 2017. Residual Stress Measurements on the TIG-Weldjoint of 57Fe15Cr25Ni Austenitic Steel for Structure Material Applications by Means X-Ray Diffraction Techniques. Makara Journal of Technology, Volume 21(2), pp. 49-57 
Ramírez, A.L., Calderon, J.P., Mazur, Z., Bravo, V.M.S., Gomez, L.M., 2016. Microstructural Changes during High Temperature Service of a Cobalt-Based Superalloy First Stage Nozzle. Advances in Materials Science and Engineering, Volume 2016, pp. 1-7

Reuteler, J., 2016. FIB Artifacts and How to Overcome them- Tutorial. The Scientific Center for Optical Electron Microscopy ETH-Zürich, pp. 1-25

Sumijanto, Pane, J.S., Saragi, E., 2015. Graphite oxidation rate estimation during air ingress accident in RGTT200K, Prosiding Seminar Nasional Teknologi Energi Nuklir 2015, pp. 383-388

Taban, E., Kaluc, E., Atici, T., Kaplan, E., 2012. 9-12\% Cr Steels: Properties and Weldability Aspects, The Situation in Turkish Industry. In: Proceeding of the $2^{\text {nd }}$ International Conference on Welding Technologies and Exhibition, Ankara-Turkey, pp. 203-212

Tovar, J.F., Lazar, F., Marichy, C., Brylinski, C., 2017. Influence of the Lattice Mismatch on the Atomic Ordering of ZnO Grown by Atomic Layer Deposition onto Single Crystal Surfaces with Variable Mismatch (InP, GaAs, GaN, SiC). Condensed Matter, Volume 2(3), pp. 2-8

Wahyono, I., Salam, R., Parikin, Dimyati, A., 2015. Characterization of Micro-structure by using SEM and XRD on the Corrosion Resistance Properties of SS430 and Non-commercial F1Steel. In: Prosiding Seminar Nasional XI SDM Teknologi Nuklir, Volume 2015, pp. 112117

Zhang, X., Li, Y., Xu, Z., Kong, X., Han, L., 2017. Preparation of $\mathrm{MgB}_{2}$ Superconducting Microbridges by Focused Ion Beam Direct Milling. In: IOP Conference Series: Materials Science and Engineering 167, pp. 1-7

Zinkle, S.J., Snead, L.L., 2014. Designing Radiation Resistance in Materials for Fusion Energy. Annual Review of Materials Research., Volume 44, pp. 241-267 